\title{
Assessing Urban Parks of District 13 of Mashhad Municipality
}

\author{
Zahra Parsanik, Abbas Maroofnezhad \\ Department of Geography, Mahshahar Branch, Islamic Azad University, Mahshahar, Iran \\ Email: abbas.maroofnezhad@gmail.com
}

How to cite this paper: Parsanik, Z. and Maroofnezhad, A. (2017) Assessing Urban Parks of District 13 of Mashhad Municipality. Open Journal of Geology, 7, 457-464. https://doi.org/10.4236/ojg.2017.74031

Received: October 31, 2016

Accepted: April 17, 2017

Published: April 20, 2017

Copyright $\odot 2017$ by authors and Scientific Research Publishing Inc. This work is licensed under the Creative Commons Attribution International License (CC BY 4.0).

http://creativecommons.org/licenses/by/4.0/

\section{(c) (i) Open Access}

\begin{abstract}
Due to the shortage and poor distribution of per capita green space in the city of Mashhad, this descriptive-analytic research emphasized on practical aspects and information collection based on field survey. This study was carried out using SPSS of version 19 (SPSS: the name of a family of computer software that is used for statistical analysis). To study the status of each research component, one sample T-Test was used and for comparison and ranking of research components in all regions and each region, Friedman test was applied. Accordingly, after identifying the parks in district 13 of Mashhad Municipality, six indicators of beauty, security, access, distribution-dispersion, areascope were prioritized, examined, and analyzed. According to the results of one sample T-Test, the average of beauty component is more than the mean 5 . On the other hand, significance level of this component is less than 0.05 . According to this average and significance level of the test, it can be concluded with a confidence of over $95 \%$ that the status of beauty index is desirable. According to the results of Friedman test in all areas of district 13 of Mashhad Municipality, indexes of beauty, distribution-dispersion, and security are of utmost importance. As well, indexes of access (transportation), available facilities, and area-scope were respectively placed in the fourth to sixth position.
\end{abstract}

\section{Keywords}

Assessment, Urban Parks, District 13 of Municipality, City of Mashhad SPSS, One Sample T-Test, Friedman Test

\section{Introduction}

Parks and green spaces are a blessing for citizens. The correct use of these spaces will improve the life quality of citizens and non-use of such spaces will lead to gathering of gangs, increase in crimes, and offenses which will cause social insecurity for citizens [1]. Consequences of urban development and complexities of 
environmental problems have necessitated availability of green space and their expansion [2]. On the other hand, we can say that the main objective in designing green space is to achieve its social and psychological effects and make man and nature closer to each other as much as possible. However, we can expect social and psychological yield from the green space function in city's physical construction and environmental performance [3]. One of the main goals of urban studies is to create balance. If localization and distribution of urban utilities and applications, including green space, are balanced, all segments of the society will take advantage of them as far as possible. So, the concept of per capita green space can only be used for that type of green space which is provided for leisure, play, and recreation. Due to improper utilization of land and water resources, Iran is placed at a level lower than worldwide standards in terms of green space. According to the standards of Department of Housing and Urban Development, per capita green space suitable for Iran cities is $12-15$ square meters. This is while in many cities, the per capita green space is less than $30 \%$ of these figures. Accordingly, one of the issues in the field of localization is determining the optimal location for parks and urban green spaces. Establishment of urban parks deserve extensive studies due to their impact on the quality of urban life as well as the financial burden they impose on municipalities without direct return of capital and profits [4].

\section{Methodology and the Study Area}

This is a descriptive-analytic study in which qualitative and quantitative methods are used for data collection and analysis. Organizational statistic was also investigated in detailed design to determine the population, area, per capita, etc. in Mashhad. First, items were prepared in the form of 9 indicators of facilities, beauty, security, access, distribution-dispersion, and area-scope, which were distributed among 377 residents in Samen area and its thirteen parts. Seventy-five questionnaires were also distributed among municipality experts (Department of Green Space or Regional Municipality and Municipality District). Finally, various indicators were weighted and analyzed by experts to measure the quality of parks. Mashhad is a metropolis in northeast of Iran and the capital of Khorasan Razavi province. In the Afsharian Era, it was the capital of Iran. With an area of 328 square kilometers, Mashhad is Iran's second largest city after Tehran. According to the 2011 population and housing census, Mashhad is the most populous city of Iran after Tehran with a population of 2,766,258 people. This city has 13 municipality districts. Samen District as district 13 of municipality is bound on the west to Noghan Neighborhood (Sector 2) and is located between Holy Shrine and Shirazi Ave., Shohada crossroad, Ayatollah Behjat St., RahAhan Square, Shahid Kamyab Blvd., Moqadam Tabarsi Crossroad. It is bound on the south to Eidgah Neighborhood (Sector 4), between the Holy Shrine, Navab Safavi St., Panj-Rah Square, 17 Shahrivar St., 17 Shahrivar Square, Bazaar Reza, and Beytolmoqadas Square. On the east, it is bound to Mir Neighborhood (Sector 3), between the Holy Shrine, Tabarsi St., Mogh'em Tabarsi Crossroad, 
Vahdat Blvd., Panj-Raah Square, and Navab Safavi St. It is also bound on the left to Chahar-Bagh Neighborhood (Sector 1), between the Holy Shrine, Beytolmoqadas Square., Shahid Andarzgoo St., Khosravi Crossroad, Azadi St., Shohada Crossroad, Shirazi St. Total area of Samen district is 298 hectares and according to the latest census in 2011, population of the region is estimated about 21,465 people, out of which 10,737 are male and 10,719 are female constituting a total of 6552 households.

\section{Materials and Methods}

The research method is descriptive-analytical and this is an applied-theoretical study. Its theoretical foundations are based on documentary studies, library and field studies, and visiting relevant agencies and organizations. The criteria used for localization are selected based on positioning criteria. Localization is a multiple-criteria decision-making ( $\mathrm{MCDM})$ process which can be done using cellular models. Hence, when selecting the software, we should notice that the software must support the raster model in addition to the vector model. In addition, it should be able to use MCDM rules. Finally and after combining the weighted layers obtained from these operations, priority areas for ranking parks of the study area were identified.

\section{Theoretical Foundations}

Biodiversity and environment protection, reduced air pollution and noise, air freshening, overshadow and microclimate adjusting, helping to slow the flow of flood, improved water quality, creating permeability for water absorption, and creating opportunities for historical and environmental studies are some of the important ecological functions of urban green spaces. Opportunities for historical and environmental studies are some of the key ecological functions of urban green space [5]. Creating proper places for sports and recreation to maintain human health and availability of these spaces for all residents, and creating a peaceful environment in the city can be regarded as some important factors for the social health. In most discussions, parks and urban green spaces are emphasized as a crucial solution which can enhance the quality of urban social life [6] [7], the contemporary urban critic believes that park should be a place where is full of life, a place where there are cultural, commercial, and residential activities. A number of urban districts have such valuable focal points of life which seem appropriate for building local parks or public squares [8]. Accordingly, localization of green spaces should obey some principles such as centrality, hierarchy and access. The concept "centrality of green space" means that the green space should be localized in the center of neighborhood, area, or urban district as far as possible. As well, green spaces on different scales ranging from neighborhood, regional parks, etc. must comply with their corresponding physical structures. For instance, regional parks should be recommended in the area [9] [10] [11]. Various types of parks along with their areas, functional radius, and authorized activities are shown in Table 1. 
Table 1. Types of parks and their authorized activities.

\begin{tabular}{cccc}
\hline Authorized activities & Radius of Action & Area & Type of the park \\
\hline Children's playground, a place to sit and control children & $200 \mathrm{~m}$ & Less than 0.5 hectare & Neighborhood \\
Leisure, walking, reading newspaper & $400-600 \mathrm{~m}$ & $1-2$ hectares & Local \\
Leisure, sitting, walking, running, biking, skating, etc. & $800-1200 \mathrm{~m}$ & $2-4$ hectares & Zonal \\
Ceremonies and gatherings, running, team sports, etc. & $1500-2500$ & $4-6$ hectares & Regional \\
All other activities in the park can accommodate & $25-35$ minutes of driving & More than 10 hectares & Urban and Regional \\
\hline
\end{tabular}

Table 2. Urban park requirements.

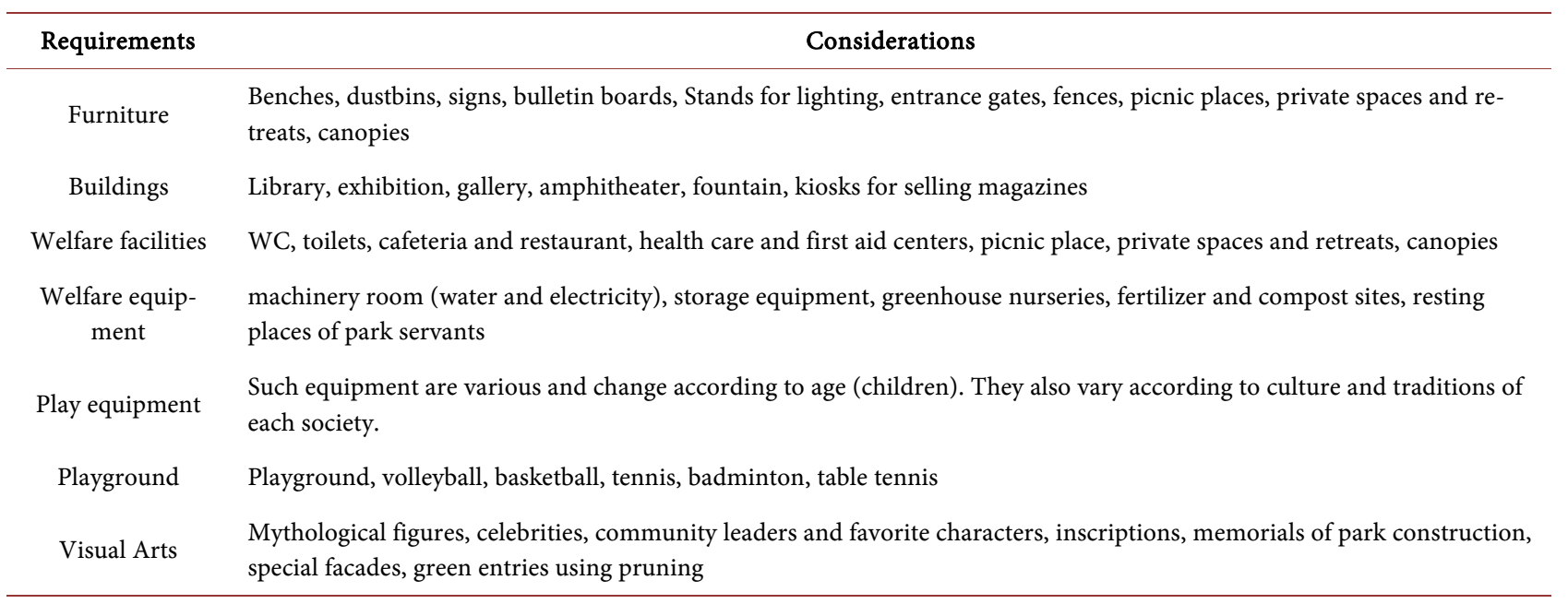

In a general classification of non-living components of parks, the elements can be divided into two categories. First category: installations which include the main structural elements and some recreational facilities which are mostly immovable and are built within the area of green space. They include security sector, entrance gate, machinery room, warehouse, and library as well as commercial, service, and cultural stores. Second category of facilities is the movable elements that are installed in appropriate locations of green space and relocating or changing them is easily possible. These are the urban park furniture, including panels, light fixtures, passages, tables, benches, etc. Table 2 shows various types of parks and their authorized activities [4].

\section{Findings}

Based on geographic, social-economic, and physical knowledge of the study area, influencing factors (criteria) were identified. Accordingly, after identifying the parks in district 13 of Mashhad Municipality, 6 indicators of facilities, beauty, security, access, distribution-dispersion, and area-scope were prioritized. In order to study the status of each factor in the research, one sample T-Test was used. One-ample T-Test: this test is used to determine significant differences between the mean of a variable with a fixed value which is called the test value. The most important point in using one sample T-Test is selecting the test value which should indicate a midpoint. In the present study, according to the in- 
tended range of responses, the test value was considered as 5. If the average of replies in each of the component variables is more than 5 , the status of that component will be favorable. Otherwise, the studied variable will not be in good condition in terms of the target population. In the intended test, hypotheses $\mathrm{H}_{0}$ and $\mathrm{H}_{1}$ are used to check the average of community views.

$$
\begin{aligned}
& \text { Relation (1) } \\
& \mathrm{H}_{0}: \quad \mu_{x} \leq \mu_{0} . \\
& \mathrm{H}_{1}: \quad \mu_{x} \geq \mu_{0} .
\end{aligned}
$$

According to the above-mentioned facts, $\mu_{0}=5$. In this test, decision will be made according to the proposed P-Value. If its value is less than the test level $(\alpha)$ and the bounds of confidence interval (mean difference with the test value) are positive, $\mathrm{H}_{0}$ is rejected and otherwise, there is no reason to reject $\mathrm{H}_{0}$. Test value in this study was considered as 0.05 . In this test, $\mathrm{H}_{0}$ and $\mathrm{H}_{1}$ hypotheses are stated as equation (2) for investigating the average of community views.

$$
\begin{aligned}
& \text { Relation (2) } \\
& \mathrm{H}_{0}: \quad \mu_{x} \leq 5 . \\
& \mathrm{H}_{1}: \quad \mu_{x} \geq 5 .
\end{aligned}
$$

According to the data of Table 3, we see that mean value of beauty index is more than the average 5. The significance level for this component is less than 0.05 . As a result, according to this mean and significance level of the test, we can conclude with a confidence level of over $95 \%$ that beauty index has a desirable status. The means of security and distribution-dispersion components are greater than 5. On the other hand, significance level of these components is more than 0.05 . As a result, according to this mean and significance level of the test, it can be concluded with a confidence level of over $95 \%$ that components of security, and distribution and dispersion have an average status. Means of components of available facilities, access (transport), and area-width are less than the average 5. The significance level of these components is also less than 0.05 . As a result and according to this mean and significance level of the test, we can conclude with a confidence level of over $95 \%$ that components of available facilities, access (transport), and area-scope have an undesirable status. For comparison and ranking of the research factors throughout district 13 of Mashhad Municipality, Friedman test was used. The test can be used for issues related to

Table 3. Test results for determining the mean of research components.

\begin{tabular}{lcccccc}
\hline \multicolumn{1}{c}{ Test result } & $\begin{array}{c}\text { Significance } \\
\text { level }\end{array}$ & T Statistic & $\begin{array}{c}\text { Degree of } \\
\text { Freedom }\end{array}$ & $\begin{array}{c}\text { Standard } \\
\text { Deviation }\end{array}$ & Average & Hypothesis \\
\hline Rejection of H0 hypothesis & 0.000 & -4.635 & 376 & 2.33 & 4.44 & Available facilities \\
Rejection of H0 hypothesis & 0.000 & 4.398 & 376 & 2.17 & 5.49 & Beauty \\
Rejection of H0 hypothesis & 0.381 & 0.876 & 376 & 2.58 & 5.12 & Security \\
Rejection of H0 hypothesis & 0.008 & -2.673 & 376 & 2.50 & 4.66 & Access (transport) \\
Rejection of H0 hypothesis & 0.136 & 1.495 & 376 & 2.27 & 5.18 & Distribution and dispersion \\
Rejection of H0 hypothesis & 0.000 & -7.652 & 376 & 2.19 & 4.14 & Area/ Scope \\
\hline
\end{tabular}


plans with repeated measures. In plans with repeated measures, each subject is a record of data with $\mathrm{k}$ variables. The scores resulting from $\mathrm{k}$ situations or opportunities enter these variables. The researcher is interested in determining the significant changes of subjects in all mentioned positions or opportunities. To that end, Friedman test (Relation 3) compares the medians of variables and reviews significance of these differences. In this test, findings of the variables are ranked in each of the records and using the average ratings of variables in the sample, equality assumption of medians of variables is tested (Table 4).

Relation (3)

$X_{1-a}^{2}(n-1)$

$\mathrm{H}_{0}$ : Median of all variables is equal.

$\mathrm{H}_{1}$ : There are at least two variables whose medians are unequal.

Regarding $\mathrm{n}$ studied variables, if the statistic $\chi^{2}$ is greater than $\alpha$ (test error) and $\mathrm{n}-1$ (the degree of freedom), then $\mathrm{H}_{0}$ (equality of medians) is rejected which means there is at least one variable whose median is significantly different with another tested variable. Otherwise, there is no reason to reject Ho hypothesis and medians of all tested variables are equal. If $\mathrm{p}$-value is less than the error level, then $\mathrm{H} 0$ is rejected. Otherwise there is no reason to reject this hypothesis.

Table 5 shows respectively the sample size, $\chi^{2}$, DOF, and significance level. As can be seen in the above table, in a significance level of $\alpha=0.05$, the test statistic is less than 0.05 . Hence, the equality assumption of medians is rejected. According to Friedman test results in all regions, beauty, distribution and dispersion, and security are of utmost importance. As well, factors of access (transport), available facilities, and area/scope were respectively ranked fourth to sixth.

\section{Conclusions and Recommendations}

In order to test the research hypothesis indicating that "it appears that quantitative and qualitative situation of parks in Mashhad Samen area is inappropriate",

Table 4. Average rate of indexes throughout district 13 of Mashhad Municipality.

\begin{tabular}{ccc}
\hline$\#$ & Variable & Average ratings \\
\hline 1. & Beauty & 4.08 \\
2. & Distribution and dispersion & 3.76 \\
3. & Security & 3.71 \\
4. & Access (transport) & 3.34 \\
5. & Available facilities & 3.21 \\
6. & Area/ Scope & 2.90 \\
\hline
\end{tabular}

Source: author.

Table 5. Results of Friedman test on the indicators throughout district 13 of Mashhad Municipality.

\begin{tabular}{cccc}
\hline P-value & $X^{2}$ & DOF & No. \\
\hline 0.000 & 127.941 & 5 & 377 \\
\hline
\end{tabular}

Source: author. 
we studied the per capita park (green space), and distribution of parks across this region and access to them. Results showed that per capita green space of Samen area for citizens is almost less than half of national average and is 5.1 individuals per square meters ( $7-12$ meters with an average of 9.5 meters) equal to a quarter of global standard. Accordingly, after identifying the parks in district 13 of Mashhad Municipality, six indexes of facilities, beauty, security, access, distribution-dispersion, and area-scope were prioritized and analyzed. Based on the results of one sample T-Test, the mean of beauty factor is more than 5. On the other hand, the significance level for this component is less than 0.05. According to this average and significance level of the test, it can be concluded with a confidence of over $95 \%$ that beauty index is in a desirable condition. With regard to the results of Friedman test in all areas of district 13 of Mashhad Municipality, indices of beauty, distribution and dispersion, and security are of utmost importance. Indicators of access (transport), available facilities, and area-scope were respectively ranked fourth to sixth. On the other hand, raising the quality level of parks and green space is a key step to provide physical and mental health. Enhancing productivity and improving performance of parks can be achieved through deep attention and thought-provoking attitude toward the views of citizens on the social consequences of construction and expansion of green spaces. Relevant authorities are expected to seriously consider the following guidelines:

1) Localization and quality of access routes to the parks must be considered carefully by experts, especially parks in high population density and congested areas for preventing any traffic jams.

2) Emphasis on the physical and spatial structure of parks e.g. increasing installations and equipment of the park, construction of new spaces, building parking lots and park furniture.

3) To reduce some undesirable effects and social consequences in parks, such as increased illicit relations, drug dealing, etc., capability and potential of other government organizations, institutions, and agencies and even private sector should be used in addition to municipalities.

4) Services and facilities for all classes and ages should be considered by responsible institutions (playground, leisure, and sports equipment for all ages and gender groups) so that people can take a walk to the park and enjoy the facilities.

5) Paying more attention to cleanliness and improving sanitation of toilets in parks of this region is of great importance. On the other hand, number of bathrooms is very low in comparison with the high number of pilgrims and visitors in some parks, especially in the spring and summer. Because a healthy and sustainable city is dependent on providing a favorable hygienic environment.

\section{References}

[1] Iran Nejhad Parizi, M.H. and Tajamolian, M. (2015) Urban Gardens and Green 
Spaces. Yazd University Press, Croatia.

[2] Bahrami, A. (2011) Investigating the Relationship between Construction of Green Spaces and Social Security and Crime of Citizens. Journal of Social Security Studies, $5,12-31$.

[3] Taghvayi, M. and Shahverdian, M. (2003) Planning and Design of Urban Green Space and Its Interaction with Human and Environment. Journal of Municipalities, 12, 22-29.

[4] Jacob, J. (2007) Death and Life of Great American Cities. Translation, Hamidreza Parsi and Arezou Aflatouni, University of Tehran, Tehran.

[5] Rostam, K.P. and Leghayi, H. (2004) Design Principles of Green Space in Residential Environments. Building and Housing Research Center, 269 p.

[6] Sa'eid, N.A. (2006) The Green Book of Municipality. Urban Development, Municipality Publications, Iran.

[7] Salehi, A. R.M., Afrasyabi, M.M., Davoodi, M. and Mojhdahi, B.R. (2014) Assessing the Spatial Distribution of Urban Parks Using Network Analysis. Journal of Urban Management, 32.

[8] Majnounyan, H. (1995) Discussions on Parks, Gardens and Promenades. Publications of Department of Parks, Green Spaces and Promenades, Tehran.

[9] Kaplan. R. (1992) The Psychological Benefits of Nearby Nature. In: Reld, D., Ed., The Role of the Horticulture in Human and Social Development, Vol. 6, Timber Press, Arlington.

[10] Ulrich. R.S. (2002) Health Benefits of Gardens in Hospitals. Plants for People International Exhibition Florida, Florida, USA.

[11] Wright, F.L. (2000) Brodacre City: A New Community Plan. In: Legate, R.T. and stout, F., Eds., City Reader, Routledge, London and New York.

\section{Scientific Research Publishing}

Submit or recommend next manuscript to SCIRP and we will provide best service for you:

Accepting pre-submission inquiries through Email, Facebook, LinkedIn, Twitter, etc. A wide selection of journals (inclusive of 9 subjects, more than 200 journals)

Providing 24-hour high-quality service

User-friendly online submission system

Fair and swift peer-review system

Efficient typesetting and proofreading procedure

Display of the result of downloads and visits, as well as the number of cited articles

Maximum dissemination of your research work

Submit your manuscript at: http://papersubmission.scirp.org/

Or contact ojg@scirp.org 